\title{
A Qualitative Study of Iranian Candidates' Awareness, Expectations and Motivational Factors Related to Nose Job Surgery (Rhinoplasty)
}

\author{
Farzad Najjarzadehghalati ${ }^{1 *}$ (1), Christoph Gradmann ${ }^{2}$ (1), Reza Kaboodkhani ${ }^{3}$ (C)
}

\begin{abstract}
${ }^{1}$ Master of International Community Health Program, Institute of Health and Society, Faculty of Medicine, University of Oslo, NORWAY ${ }^{2}$ Professor, Department of Community Medicine and Global Health, Faculty of Medicine, University of Oslo, Oslo, NORWAY

${ }^{3}$ Assistant Professor, Department of Otorhinolaryngology, Head and Neck Surgery, Shiraz University of Medical Science, Shiraz, IRAN *Corresponding Author: farzadnajarzadeh@yahoo.com
\end{abstract}

Citation: Najjarzadehghalati F, Gradmann C, Kaboodkhani R. A Qualitative Study of Iranian Candidates' Awareness, Expectations and Motivational Factors Related to Nose Job Surgery (Rhinoplasty). Electron J Gen Med. 2022;19(2):em353. https://doi.org/10.29333/ejgm/11564

ARTICLE INFO

Received: 11 Jul. 2021

Accepted: 1 Nov. 2021

\begin{abstract}
Introduction: Interest to undergo nose job surgery, known as rhinoplasty, has grown among different strata of Iranian society. As an elective and non-emergency surgery, it is always accompanied by complications like other invasive surgeries. However, little is known about candidate's awareness regarding these problems and also their expectations toward this famous plastic surgery.
\end{abstract}

Objectives: To assess the awareness level of candidates as well as their expectations and motivational factors, and the reasons behind the high rates of nose job surgery in Iran.

Methods: Sixteen men and women aged 20-42 who were decided to undergo nose job surgery for first time in near future were interviewed using a semi-structured interview format. Twelve face-to-face with four telephone interviews (using WhatsApp application) were conducted. The research questions explored participant's information level, persuasive reasons, and their achievements after having surgery. The interviews were audio recorded and then transcribed verbatim. Conventional content analysis was used to evaluate data.

Results: The results of the analysis showed that the participants and even their family mostly had preliminary and superficial information regarding surgery complications. Negative feedback or misplaced judgements in the community, family and friends, media advertising, and scientific and technological advances are act as motivating factors. The tendency to undergo nose job surgery is not always for the sake of beauty. Sometimes it is done for therapeutic purpose. Improving the quality of life, giving better opportunity to find new friends or social interaction, increasing self confidence in public place, self-satisfied and freedom from obsession are counted as further achievements.

Conclusion: The awareness level regarding nose job surgery was limit and superficial. People usually think optimistically about the results and count this surgery as a tool by which in addition to gaining beauty, they can gain higher social prestige and something new in life and get rid of daily life monotony. Mutual cooperation of psychologists and surgeons is necessary. This important can increase candidates' satisfaction by identifying motivational criteria and their expectations.

Keywords: awareness, motivation, rhinoplasty, Iran

\section{INTRODUCTION}

Cosmetic plastic surgery has increased in the recent years all around the world. One of the most popular plastic surgeries is rhinoplasty (known as nose job), in which the nose is reshaped in order to increase facial beauty and harmony between the components of the face. Initially, rhinoplasty was confined to repairing damage, but in modern times it has been used to change the nose shape for aesthetic purposes. Before modernity, human beings looked at beauty and appearance according to traditional standards, but today, the trend towards beauty has reached the stage of appearance and selfexpression. Cosmetic surgery has now become a deceptive factor and a tool for people's luxury, which led to the establishment of unrealistic expectations in individuals and the distortion of facts about its true nature.
According to the report of International Society of Aesthetic Plastic Surgery (ISAPS), in 2017 the rate of nose job increased by $11 \%$ compared to previous year [1]. But in 2018, reduced slightly, so that Brazil, India, and USA have the top rank regarding number of nose job procedures [2].

It is said anecdotally that Iran is one of the countries with highest rate of cosmetic rhinoplasty in the world. In 2013 Iran ranked fourth in term of the number of nose job surgeries that were done [3]. But no specific reports have been received since then. This may suggest that nose job occur more widely than what has been reported officially in Iran, because significant number of rhinoplasty procedures are performed by unlicensed practitioners in the private clinics, the exact number of which is not reported [4].

It may be thought that cosmetic surgeries are only belong to the affluent strata of society, but it should be noted that due 
to cultural developments and changes in people's ideals, today nose job surgery has become very common among men and women from middle and even low-income strata. This tendency has led to spend exorbitant and heavy costs that impose heavy economic pressure on families, and also leading to financial burden on healthcare system [5].

The majority of research published from 2005 about the nose job surgery has focused on establishing links between psychological and personality aspects of the individuals, and also investigating and comparison of the quality of life before and after surgery. For example, Mianroodi et al. [6] had found that nose job surgery is very popular among people with obsessive and narcissistic characteristics, and the main reasons for wanting rhinoplasty were beauty and because it is fashionable [6]. Based on literature review conducted by Zojaji et al. [7] the quality of life improved six months after surgery and over time [7]. Recent findings in Germany can confirm these results [8]. Mozaffari Niya interviewed twenty-one men and women who had undergone face cosmetic surgery to explore their personal motivations which leads to accepting the risk of surgery, and described three main themes as tempting factors: feelings of inferiority, Escape from loneliness and Fear of the unseen by relatives and society [9]. Other prior researcher reported that cosmetic surgery patients are often expect extra-physical benefits such as higher self-esteem and better sex life [10].

Correct and adequate information and understanding expectation are often issues of concern among Plastic surgeons and patients, which have direct impact on patient's decision making. A study from Saudi Arabia revealed that candidates are not often aware of post operation complications and have superficial information [11]. To avoid or reduce complications and dissatisfaction after rhinoplasty, it is better to consider and estimate one's personality traits, goals, and expectations from this procedure [12].

However, limited studies in Iran have so far investigated patient's awareness about post operation complications, motivation and expectation factors. In this article, we draw on in-depth interview with participants who were waiting for surgery in order to explore these missing factors and also influenced criteria, which push them to perform nose job surgery.

Although nose job surgery is not an emergency surgery and is chosen freely by individuals, but it has its own complications and risks like any other type of surgery. Therefore, these questions arise that to what extend are candidates aware of surgery complications? What are their main motivations and expectations factors toward nose job surgery? By qualitatively examining these questions, we can also find the reasons behind the high rates of nose job surgery in Iran. finally, we aimed to gain insight into important factors and criteria, which patients will achieve with nose job surgery.

\section{METHODS}

\section{Participants}

Sixteen participants ( 12 women, 4 men), aged from 20 to 42 years with a mean age of 31 years by using purposive sampling technique were recruited. Data were collected between September 2019 up to January 2020. In order to obtain good validity and minimize bias some exclusion and inclusion points were considered.

Exclusion criteria included health care profession (e.g., doctors, students, health care assistants), and those who want to do nose job surgery for the second or more times (revision surgery), because they might have obtained information and good experience through previous surgery and this interfered with the purpose of the study, which was to assess preoperative information. We selected candidates who decided undergo nose job surgery for first time and those over the age of eighteen.

\section{Procedures}

Prior to carrying out this study, it was tried to identify and address ethical and moral dilemmas in order to protect all participants from potential harm. So, at the first step, we received the approval of the Norwegian Center for Research Data (NSD). This study also received approval from the ENT department of Shiraz University of Medical Science and director confirmation of two hospitals to ensure adherence to ethical research standards. Participants were those who received admission paper from their surgeon and presented in hospitals to register themselves for future surgery. Those who expressed interest in participating in our study were given an invitation letter with a consent form which included information regarding the research purposes and procedures, extent of use of the collected data, discard of data, protection of privacy, rights of the participants including the right to withdraw from the research project and refuse to answer any interview questions. We also added our phone numbers and email addresses to allow participants to clarify any queries and to determine the location of the interviews. Both researchers and interviewees agreed to comply with research ethics through a signed informed consent form. Four women who indicated interest in participating but living in other cities were recruited in one-on-one phone interview using WhatsApp application after sent us signed consent form by post. The phone interviews were between 20 and 40 minutes in duration, but the face-to-face interviews were taking longer.

\section{Interviews}

Open ended, semi structured, in-depth interviews were employed in this study because open ended allows participants to discuss their opinions, views and experiences fully in detail and also allows both the interviewer and participant to seek any clarification necessary. According to Polit and Beck [13] with the use of semi structured interviews we have prepared a topic guide or a certain number of questions to be covered with each participant. According to participant's answers, more in-depth questions such as "what did you mean by this statement", or "can you explain more" were asked. By using questions involved general information regarding the participant's personal history and demographic detail we started interviews. This stage helps to break the ice and allowed to focus on main topic. A set of broad questions were developed that addressed three general areas: (a) participant's main motivations and expectations toward nose job surgery and influenced factor, (b) awareness about this surgery complications, (c) the reasons behind high rate of nose job surgery in Iran. In addition, the participants were encouraged to talk freely to provide any other relevant information not addressed by the researcher. Regarding phone interviews, it should be noted that the questions were asked 
one by one through WhatsApp software. Similarly, the participants recorded their answers and returned them. This method allows participants to express personal information in their spare time and in complete peace and comfort without any stress of face-to-face interviewing. Interviews were done at workplace, café, with a few in the park. With each participant's consent, the interviews were recorded and in further stage transcribed verbatim.

\section{Data Analysis}

Conventional content analysis method was used to evaluate data. This approach is used when the researcher aim is to describe and gain a richer understanding of a phenomenon, which there is little literature that supports and gives information about a specific topic [14]. Each participant's transcript was read several times to identify and label desired themes which were in line with the aims and objectives of the study. In the next stage similarities and relevance of these themes checked out and formed clusters of concepts for each transcript. Finally, all these themes and clusters verified together to find any new sub or master theme which reflect participant's perceptions regarding nose job surgery. This process continued until no new themes could be identified.

In order to ensure the trustworthiness and validity of study after transcribed each interview, the encoded text was photographed or scanned and sent to participant in order to confirm. Also, to validate the suggested themes which found by first author, collaborative author re-read the translated copy, identifying themes and comparing these to the initial reading. At this stage some information were added, refined and some were discarded.

\section{RESULTS}

Undoubtedly, any type of surgery has its side effects and risks. But it is very interesting to hear different attitudes of people toward surgery. Overall, the data from the 16 participants (which personal characteristics of them listed in Table 1), reflected that most of these people consider surgery as a tool in the first place and give less priority to the therapeutic aspect. The means by which they can gain something new in life and get rid of the monotony in daily life, a means that is considered as a symbol of higher prestige and enhance beauty. For example, a 25-year-old female participant stated her view as follow:

\footnotetext{
"Although nose surgery is an invasive surgery, but it can make me more beautiful and is worth the risk. Nowadays it is very common among girls and boys and considered as a symbol of high prestige".
}

Except the therapeutic aspect, numerous factors pushed participants to think and make the decision to perform a nose job surgery. Almost all of the respondents interviewed mentioned that they had friends, family or acquaintances who had undergone nose job surgery and they also offered to do it. In this case a 36-year-old male participant said:

\footnotetext{
"It's been less than a year since I started thinking about this surgery. Some of my friends had the surgery and upon seeing them I decided to do it by the same surgeon, because their facial changes were very noticeable".
}

Table 1. Personal characteristics of the participants

\begin{tabular}{clc}
\hline & Variable & $\mathbf{N}$ \\
\hline \multirow{2}{*}{ Gender } & Male & 4 \\
\cline { 2 - 3 } Age & Female & 12 \\
\hline \multirow{2}{*}{ Marital status } & 20-30 years old & 9 \\
\cline { 2 - 3 } & S30 years old & 7 \\
\cline { 2 - 3 } & Single & 10 \\
\cline { 2 - 3 } & Married & 4 \\
\hline \multirow{2}{*}{ Level of education } & High school diploma & 2 \\
\cline { 2 - 3 } & Academic & 3 \\
\hline \multirow{2}{*}{ Occupation status } & 13 \\
\cline { 2 - 3 } & Employed & 12 \\
\hline
\end{tabular}

One of the inappropriate behaviors which the vast majority of participant $(\mathrm{N}=12)$ could recall at least one negative experience was that, people's appearance is judged directly and people express their opinion clearly, which sometimes led to negative emotion and feeling, irritation, stress and especially obsession. A female participant said:

\begin{abstract}
"At first I had no idea about having a nose surgery. In my workplace, friends and co-workers said that if you had surgery you would have a much more beautiful face. They have said this many times over and over. Since then, it has come to my mind that there may be a defect or flaw in my face that my colleagues keep repeating. This thought always bothered me, so I was always cautious and stressful in social relationships and when I wanted to talk to someone".
\end{abstract}

However, these negative comments and experiences also involved discussions with friends, family members, and colleagues in the workplace for some participants.

Encouraged by the mass media and the virtual world (Internet), negative self-concept, and the acceptance of nose job surgery (rhinoplasty) as a criterion of beauty in society were others influential factors in decision making.

Among participants in this study, 3 female and 2 male suffered from respiratory disorders such as nasal congestion, and nasal septum deviation. Their top priorities were to treat these problems. The rest of participant consider just the beauty aspect of this surgery. The opinion of a 24-year-old male participant was interesting:

"Two years ago, my nose was broken during exercise
and my nose was severely distorted in appearance,
which greatly affected my breathing. I get shortness
of breath at night and during sleep. My main goal is to
improve my breathing and because I accept the risk
of anesthesia and surgery, I want to make some
changes to its beauty at same time".

There are various possible complications after nose job surgery. The familiarity and awareness of the participants with some postoperative complications of rhinoplasty based on their own words were as follow: bruises around the nose and postoperative bleeding $(\mathrm{N}=9)$ inflammation $(\mathrm{N}=7)$, respiratory disorder and airway obstruction $(\mathrm{N}=7)$, olfactory disturbance $(\mathrm{N}=5)$, pain $(\mathrm{N}=5)$, allergy $(\mathrm{N}=5)$, revision or reconstruct surgery $(\mathrm{N}=4)$, Numbness and runny nose $(\mathrm{N}=3)$, infection $(\mathrm{N}=3)$, mismatch with other facial components $(\mathrm{N}=3)$, anesthesia complication $(\mathrm{N}=2)$, dissatisfaction with the new face $(\mathrm{N}=2)$ and remaining $\operatorname{scar}(\mathrm{N}=2)$. 
The most important ways and source of informing about these complications were:

- Social media, websites and chat forums.

- Tips and advices from friends who underwent this surgery.

- Applicants who had undergone surgery and had referred to doctor's office and clinic for post-operative visit.

- Consultation with physicians.

- Medical magazines, booklets, and articles.

Regarding the level of information and awareness of participant's parents about nose job surgery, mostly reported $(\mathrm{N}=10)$ that their parents have no related knowledge and information. The rest had general or superficial information based on observation of similar cases in society. According to this, twelve participants reported that their parents disagreed with them to do this cosmetic surgery, 3 were agreed, and only one was neutral.

Factors which considered by the participants to select a surgeon were (in order of decreasing frequency): being an ENT specialist, friend suggestion, the amount of time which a surgeon devote for counseling and applicants' guidance, being famous from the people's point of view, see work samples in internet and clinics, and registered scientific articles.

On the other hand, they also had criteria for choosing a hospital for their future surgery such as: low density and crowding of patients, governmental hospital because there is better control over physician and medical staff performance, be stylish, tidy, and having experienced staff, providing high quality equipment and facilities.

The participants expectations from their surgeon were mentioned as follow: surgeon must have the patience to listen to patients talk and concerns, having more consultation sessions before operation day, the surgeon himself do this surgery and not delegate work to a colleague or student and accept responsibility for his own work, quick and easy access to the surgeon after surgery in case of emergency. One of the concerns voiced by most male participant was that produce subtle changes that make the nose appear natural, with preservation of facial harmony.

All participants in this study articulated that nose job surgery will be their first cosmetic surgery experience, however there were 4 participants out of 16 who commented that they had other surgeries outside of the cosmetic category which play an important role in decision making and make them more determined to have a new surgery. For instance, in this quotation:

I was always used to wearing glasses until I had LASIK surgery three years ago. After that I didn't have to wear glasses anymore and my nose was disproportionately on my face. I was not happy with my new face without glasses, especially when I was looking in the mirror. My friends and those around me also gave me negative feedback and said that when you wore glasses you had a more beautiful face. After that I decided to try a new face ( 28 years old male participant).

From the analysis of the interviews, we identified three barriers or obstacles categories and their related reasons, which have deterrent role in performing this surgery in Iran.
1) Social barriers:

- Negative perceptions and feedback especially from the previous generation.

- People comment freely regardless of the circumstances of the applicant.

- Lack of pre-surgical psychological counseling which is often neglected.

- Not allocating enough time for clear advice and eliminating ambiguities by the doctors due to the large number of applicants.

2) Financial barriers:

- Cosmetic surgeries are not or in very low percentage covered by public and private insurances.

- High cost of surgery due to economic conditions which is not stable and change constantly.

- Getting a support such as bank loan is not an easy task and it takes a long process.

3) Political barriers:

- There is no government control over the cost of this surgery.

- The cost of surgery varies widely between hospitals and even doctors.

- Physicians with different backgrounds and specialties such as general surgery or maxillofacial surgeons perform nose surgery too and there is no proper government oversight of their work.

The reasons behind the high rate of nose job surgery in Iran from the participants' point of view were: social comparison, veil or cover as a limiting factor to express beauty, mass media that introduce ideal beauty standards and strongly influence the social comparison, the low cost of surgery in compared to other countries that causes many people as a tourist come to Iran to perform surgery, people's criticism of others looks and faces which can act as a motivating factor, nose in compare to the face is more disorganized in the Iranian race, negative body image and low self-esteem, the uniformity of daily life and a way to get rid of fatigue and daily weariness.

In investigating the effects and consequences of nose job surgery on participant's lives the following issues were raised: improving the quality of life by removing a defect such as breathing problems, feeling self-satisfied with new face, giving better opportunity to find new friends or social interaction, increasing self confidence in public place, intellectual peace and freedom from obsession. If the expected results are not achieved, depression and regret because of people's negative opinions and judgments.

\section{DISCUSSION}

The results of this study found that most of the participants considered cosmetic surgery as a normal device or facility in order to get pleasure, satisfactions and something positive in their lives regardless of its possible negative aspects and consequences as an invasive surgery. This way of thinking acts as a stimulus and is in line with the perspective of emotion theorists which state that emotion causes direct behavior and act as a motivation source [15]. 
In this research we understood that one of the seductive factors toward doing a cosmetic nose surgery was friends, family or acquaintances who had undergone nose job and they had enough satisfaction. This finding is consistent with a study from Thailand [16], which mentioned that people compare themselves with those who had similar successful surgery and created a visual identity that if they underwent cosmetic surgery, then they would achieve a same successful outcome like the others without considering the failures that might occur.

Inappropriate feedback from misplaced judgement and prejudices based on people's appearance can cause dissatisfaction, unhappiness and negative attitude toward selfimage especially during loneliness and privacy. These negative interpretations can suppress the confidence and leads to emotional distress which push persons to do cosmetic surgery as a way of escape from these disorders and obsession. This finding confirms the result of Mozaffari Niya study [9].

The media has been constantly promoting or advertising beauty patterns and related standard criteria. In this study participants discussed intentionally or unintentionally felling bombarded with ideals of aesthetic attractiveness via the media and compare their appearance with those advertised criteria and judge themselves. The result of this judgment influenced the perception that one had so far of oneself. This can be a starting point for thinking about changing face and appearance by nose job surgery. These results are in line with studies which reported that the media is the driving force behind the growing demand for cosmetic surgery [17], and with other study that noted the media by affecting the level of body dissatisfaction normalized cosmetic surgery as being an acceptable way to improve the appearance of our bodies [18].

In the next step most participants try to gather basic or supplemental information over the internet and support forums which gave them a clearer perspective and make them more awareness for the next stage. For example, same as the results of Warner's study, those who seek health information online were more likely to communicate with medical professionals about health treatments and they try to obtain more precision information than those who did not use the internet as a source of information [19].

In this study the tendency and attraction for nose job surgery was not confined just to the beauty aspect. Almost one third of participants stated that their priority was the therapeutic aspect in order to repair a defect or problem such as nasal congestion, nasal septum deviation, nose fracture, and shortness of breath (Dyspnea). At the same time, they decided to focus on beauty as well because they undertake the risk of surgery, anesthesia, and treatment cost once. Our findings are in contrast to the results of a study by Calogero et al. [20] who considered body shame as the cause of women's desire for cosmetic surgeries [20]. Also, with other study conducted by Mozaffari Niya et al. [9] which found that the increasing acceptance of cosmetic surgery is the reduced satisfaction with physical appearance and fear of being unattractive [9].

Face cosmetic surgeries are not emergency surgeries and may be associated with dangerous consequences. In our study the participants varied widely in the amount and type of information related to postoperative complications they had. The complications mainly recognized by the participants were more superficial and based on what they had seen in the surrounding community. They had no tendency to understand and obtain medical and in-depth information about complications. The most important reasons for this attitude were the following: fear of complications when they talk about it and prefer not to hear anything, consider most of them as temporary and transient, seeing or hearing negative consequences rarely when consulting with others, preferred and attention to the surgeon's work so that a good surgeon can reduce the risk of complications, and they do not like to hear because they think positively.

In addition to the social media and websites that were the biggest sources of information for participants, friends and those who underwent nose job surgery counted as second important way to make themselves aware of surgery process and consequences. In our study only one third of participant mentioned that they received information leaflets and a full explanation of risks from their surgeon while others were less well informed. It seems that when the surgeon did not provide enough information, this lack or deficiency was compensated by resources mentioned earlier. This finding is in support of a study by Paling [21], which noted that the doctors are not always effective in ensuring patients are fully aware of risks involved in medical procedures [21].

Contrary to some reports [6] indicated that the tendency to want cosmetic surgery decreased as parental information increased, we realized that the awareness level of parents and their opinion about whether or not to perform nose job surgery is not very important and in most cases ignored by the participants because despite their parent's opposition, they were determined to have surgery and even some participants did not inform parents until they registered themselves for surgery at the hospital. Concern about nose manipulation, old beliefs and difference of generations, and incompatibility of surgery due to age were stated as reasons for parental opposition. The interesting reason given by some male participants was that their parents attributed this surgery to be for girls only.

A significant factor for the success of therapy which highly influencing the satisfactions rate of a cosmetic surgery is the type of relationship and how the doctor interacts with the patient. In fact, the applicants want to build some kind of trust. This is something that our participants have mentioned many times and expected from their doctor to have more counseling sessions, because as they get closer to the day of surgery, new vague questions engage their minds. This issue is so important that our research participants considered the amount of time, which a surgeon devote for counseling and applicant guidance as one of the criteria for selecting their surgeon. This finding confirms the results of Safran's report [22], which stated establishing enough and good alliance is one of the main reasons for the success of therapy [22].

Although nose job surgery was the first cosmetic surgery for all our research participants, but some of them had surgery outside of cosmetic fields which the obtained results played an effective role on attitudes toward having future procedures. We have found that some of these results caused changes in the appearance of the person which forced them to perform additional surgery to eliminate an incompatibility or on the other hand give them experience and information that they planning to do new surgery in the future. This result is almost in line with the results from Adam's study which reported that satisfaction or dissatisfaction with the outcome did not always have a corresponding effect on attitudes toward having future procedures [23]. 
The barriers that our participants faced after deciding to have nose job surgery were divided in to social, financial and political barriers. One of the social barriers was the relationship between cosmetic surgery and the issue of psychology which is often neglected. There are many surgeons who fell that they are performing psychosurgery which means that they are making a change to the body that will also influence patients psychologically [24]. Psychological counseling along with medical counseling is important because it can help physician to understand the psychological reasons why a person may be or not be a good candidate for cosmetic surgery and also to find their expectations and act accordingly which leads to increase satisfaction rate for both sides.

In our study social comparison was mentioned frequently as a reason regarding high rate of nose job surgery in Iran. People try to interact and compare themselves with member of society in order to generate social power or superiority and show themselves as an affluent class.

\section{CONCLUSIONS}

This study has attempted to explore the awareness level of participants about the complications of nose job surgery, and also identify their expectations and motivation factors. In particular, we tried to find the reasons behind high number of such a costly and painful procedure in Iran.

The findings suggest that mass media and negative feedback or misplaced judgements from people in the community play an important role in participant's decisions to undergo nose job surgery. People usually think optimistically about the results of this surgery and count it as a tool by which in addition to gaining beauty, they can gain higher social prestige and something new in life and get rid of daily life monotony. Improving the quality of life, giving better opportunity to find new friends or social interaction, increasing self confidence in public place, intellectual peace and freedom from obsession and achieve self-satisfied feeling are also considered to be the most important achievement of this surgery. The tendencies toward nose job surgery are not always for the sake of beauty. Repairing a defect or problem such as nasal congestion, nasal septum deviation and nose fracture are counted as a therapeutic aspect of nose job surgery.

Although the majority of clients have an academic background, the familiarity and awareness with some postoperative complications were more superficial and based on what they had seen in the surrounding community. Fear of knowing the details, considering possible complications as temporarily, and be optimistic are some factors that reduce their tendency to understand and obtain medical and in-depth information.

In today's modern society, factors such as social and cultural conditions, family and friends, media advertising, and scientific and technological advances are some criteria that affect the standards of beauty in society. Psychologically, while most previous studies have focused on the effects of this surgery on individual personality and quality of life through quantitative studies, the results of this study showed that psychological counseling is often ignored or not given importance. Without psychoeducational supports and information training, clients will judge themselves with the society's beauty ideals and internalize beauty standards, which mostly lead to body shame and dissatisfaction. This sense of self-loathing can act as a stimulant to change the appearance through the use of, for example, surgery [25].

\section{RECOMMENDATIONS}

The results presented here will potentially convince physicians to communicate more effectively with candidates who are seeking nose job surgery by considering more consultation time and provide them deep information. It would be a good idea for future study to find out what kind of information the applicants need to make a logical decision for surgery.

Time constraints and not allocating enough time in doctor's office is a problem that has been repeatedly mentioned as a major challenge, not only in Iran but also in most countries of the world. If a comprehensive medical website can be setup under the supervision and control of the Ministry of Health and the government in simple language for general understanding, which includes all the necessary information such as surgical procedure, complications, care and tips before and after surgeries, medication and sample surgery video, it can act as an auxiliary tool in medical counseling. In addition to face-to-face consultation, doctors can introduce this website to patients in order to find more accurate and explicit information. This idea can increase patient's awareness and also remove ambiguities.

Cosmetic surgery has a dual effect, physically and psychologically. All clients should have psychological support as part of their care pathway [26]. It would be great if mutual cooperation of psychologists and surgeons before and after cosmetic surgery be considered as a mandatory rule in Iran. This important increase candidate's satisfaction by identifying their motivation and expectation, and understanding the reasons why people decide to have non-medically necessary surgery, and make it possible to reconsider whether or not to have surgery.

Since the number of men participating in our research was much smaller than women, it would be beneficial to look at the perceptions and expectations of two genders separately in future studies. So, we can compare them in more details because a man's world is very different from a woman.

Author contributions: All authors have sufficiently contributed to the study, and agreed with the results and conclusions.

Funding: No funding source is reported for this study.

Acknowledgements: The authors would like to acknowledge the participants of this study for sharing their valuable experiences and time. Also, we would like to express our sincere gratitude to Mrs. Saeideh Soleimani for making the necessary arrangements.

Declaration of interest: No conflict of interest is declared by authors.

\section{REFERENCES}

1. Surgery ISoAP. Global Survey Results. 2017. Available at: https://www.isaps.org/wp-content/uploads/2019/03/ ISAPS_2017_International_Study_Cosmetic_Procedures_ NEW.pdf

2. Surgery ISoAP. ISAPS Global Survey Results. 2018. Available at: https://www.isaps.org/wp-content/uploads/2019/12/ ISAPS-Global-Survey-Results-2018-new.pdf 
3. Surgery ISoAP. Global statistics. 2013. Available at: https://www.isaps.org/wp-content/uploads/2017/10/2014 -ISAPS-Results-3-1.pdf

4. Ebrahimi A, Kalantar Motamedi MH, Shams A, Nejadsarvari N. Health and social problems of rhinoplasty in Iran. World J Plast Surg, 2016;5(1):75-6.

5. Tavassoli G, Modiri F. Women's tendency toward cosmetic surgery in Tehran. 2012.

6. Mianroodi AA, Eslami M, Khanjani N. Interest in rhinoplasty and awareness about its postoperative complications among female high school students. Iran J Otorhinolaryngol, 2012;24(68):135.

7. Zojaji R, Sobhani E, Meshkat M, Javanbakht M. Quality of life after cosmetic rhinoplasty in Iran: A systematic review. J Fund Ment Health, 2018;20(5):320-4.

8. Niehaus R, Kovacs L, Machens H-G, Herschbach P, Papadopulos NA. Quality of Life-changes after Rhinoplasty. Facial Plast Surg, 2017;33(05):530-6. https://doi.org/10.1055/s-0037-1606572 PMid:28962060

9. Niya NM, Kazemi M, Abazari F, Ahmadi F. Personal motivations of Iranian men and women in making decision to do face cosmetic surgery: A qualitative study. Electron J Gen Med, 2018;15(3):em29. https://doi.org/10.29333/ejgm/ 86192

10. Stofman GM, Neavin TS, Ramineni PM, Alford A. Better sex from the knife? An intimate look at the effects of cosmetic surgery on sexual practices. Aesthet Surg J, 2006;26(1):127. https://doi.org/10.1016/j.asj.2005.11.002 PMid:19338876

11. Almohanna S, Alswidan R, Alarfaj A, Subhan Y. The Number and Awareness of Rhinoplasty and People Preferences of the Shape of the Nose. Kuwait Med J, 2016;48(2):132-8.

12. Zojaji R, Javanbakht M, Ghanadan A, Hosien H, Sadeghi $H$. High prevalence of personality abnormalities in patients seeking rhinoplasty. Otolaryngol Head Neck Surg, 2007;137(1):83-7. https://doi.org/10.1016/j.otohns.2007.02 .027 PMid: 17599571

13. Polit DF, Beck CT. Nursing research: Generating and assessing evidence for nursing practice. Lippincott Williams \& Wilkins. 2008.

14. Hsieh H-F, Shannon SE. Three approaches to qualitative content analysis. Qual Health Res, 2005;15(9):1277-88. https://doi.org/10.1177/1049732305276687 PMid:16204405
15. Baumeister RF, Vohs KD, Nathan DeWall C, Zhang L. How emotion shapes behavior: Feedback, anticipation, and reflection, rather than direct causation. Pers Soc Psychol Rev, 2007;11(2):167-203. https://doi.org/10.1177/1088868 307301033 PMid: 18453461

16. Yenchai D, Sirisook V. Affective forecasting for cosmetic surgery of Thai women: A qualitative study. Kasetsart J Soc Sci. 2018;40(3):628-634. https://doi.org/10.1016/j.kjss. 2017.12.026

17. Koning M, Zeijlmans IA, Bouman TK, van der Lei B. Female attitudes regarding labia minora appearance and reduction with consideration of media influence. Aesthet Surg J, 2009;29(1):65-71. https://doi.org/10.1016/ j.asj.2008.12.003 PMid:19233008

18. Sharp G, Tiggemann M, Mattiske J. The role of media and peer influences in Australian women's attitudes towards cosmetic surgery. Body Image, 2014;11(4):482-7. https://doi.org/10.1016/j.bodyim.2014.07.009 PMid:25129686

19. Warner D, Procaccino JD. Women seeking health information: distinguishing the web user. J Health Commun, 2007;12(8):787-814. https://doi.org/10.1080/ 10810730701672090 PMid:18030642

20. Calogero RM, Pina A, Park LE, Rahemtulla Z. Objectification theory predicts college women's attitudes toward cosmetic surgery. Sex Roles, 2010;63(1-2):32-41. https://doi.org/10.1007/s11199-010-9759-5

21. Paling J. Strategies to help patients understand risks. Bmj, 2003;327(7417):745-8. https://doi.org/10.1136/bmj.327. 7417.745 PMid:14512489 PMCid:PMC200818

22. Newhill CE, Safran JD, Muran JC. Negotiating the therapeutic alliance: A relational treatment guide. Guilford Press. 2003.

23. Adams J. Motivational narratives and assessments of the body after cosmetic surgery. Qual Health Res, 2010;20(6):755-67. https://doi.org/10.1177/104973231036 2984 PMid:20207954

24. Parker R. Women, doctors and cosmetic surgery: Negotiating the 'normal'body. Springer. 2010. https://doi.org/10.1057/9780230246645

25. Grogan S. Body image: Understanding body dissatisfaction in men, women and children. Taylor \& Francis. 2016.

26. Clarke A, Rumsey N. Surgeons are crying out for people to work with them. British Pschological Society. 2018. 